\title{
Spirituality and Mindfulness Practices of Early Childhood and Elementary Preservice Teachers: A Snapshot
}

\author{
Kelsey L. Evans-Amalu ${ }^{* 1}$, Thomas A. Lucey² \& Miranda Lin²
}

* Corresponding author: themeditationprofessor@gmail.com 1. College of Education, Georgia Southwestern State University, Americus, GA, United States. 2. School of Teaching and Learning, Illinois State University, Normal, IL, United States.

\section{Article Info}

Received: September 15, 2021

Revised: October 27, 2021

Accepted: November 22, 2021

$10.46303 / j c s r .2021 .12$

\section{How to cite}

Evans-Amalu, K. L., Lucey, T. A. \& Lin, M. (2021). Spirituality and Mindfulness Practices of Early Childhood and Elementary Preservice Teachers: A Snapshot. Journal of Curriculum Studies Research, 3(2), 207-221.

https://doi.org/10.46303/icsr.2021.12

\section{Copyright license}

This is an Open Access article distributed under the terms of the Creative Commons Attribution 4.0 International license.

https://creativecommons.org/licenses/by/4.0/

\section{ABSTRACT}

This paper describes the results of a research survey that interpreted the patterns of mindfulness and spirituality within a convenience sample of preservice teachers at a Midwest teacher education institution. Mindfulness and spiritualty represent topics of developing interest in teacher education that serve to increase candidate focus and revision of practice. Respondents completed a survey as part of a semester's project that interpreted the results of a semester-long mindfulness intervention on student mindfulness and spiritual attitudes and practices. The findings determined that participants had senses of mindfulness and self the emphasized themselves, and their external worlds, let weak connection with a higher spiritual entity. Significant differences were observed between early childhood and elementary majors.

\section{KEYWORDS}

Mindfulness; spirituality; early childhood education; elementary education; preservice teachers; teacher education. 


\section{INTRODUCTION}

Preservice teacher education programs aim to prepare graduates to function within a pre-K-12 school system equipped with the necessary pedagogical practices to succeed in the teaching profession (Darling-Hammond \& Bransford, 2005). Yet, the American public education system has undergone social, political, and cultural shifts (Zeichner, 2016) within the past decade, and many teacher preparation programs are struggling to teach and prepare the whole student for the challenging career of teaching.

Within the 21st century, the role of the teacher requires the need for more selfawareness and deep reflection (Mergler \& Spooner-Lane, 2012). Although teacher education programs embed the reflection process into their curriculums, it would behoove programs to consider using practices that aid in developing further self-awareness and mitigates professioninduced stress to create greater self-efficacy.

Research suggests that preservice teachers who clearly understand who they are will be more prepared to interact with personal and professional challenges (Caldwell \& Hayes, 2016). Yet, many teacher education/preparation programs often fail to consider the developmental process from the whole child perspective of the individual student (e.g., the teacher candidate) (Miller, 2010). In examining the spiritual dimension of student development theory and the axiology of humanism, we find that past foundational beliefs of American education promoted spiritual growth and development of the student (American Council on Education, 1937, 1949). However, when looking at teacher education and learning standards today, they often disaggregate into various cognitive, emotional, and physical elements without attention to the larger sense of the students' identities and affect. Preparing teachers with a holistic perspective of learning provides for a profound sense of awareness and valuing that invites a richer understanding of social engagement. Holistic education attends to all developmental domainsincluding the spiritual dimension, which may support preservice teachers bringing their learning from their spiritual life into the classroom (Cady, 2007; Miller, 2010; Noddings, 2010; Zhang \& Wu, 2016).

Mindfulness and spirituality are separate constructs that have often been independently used amongst teacher populations to mitigate stress and increase self-awareness and selfefficacy. The current study sought to interpret the perception of the two constructs by preservice teachers. This paper presents the results of a survey that interpreted the levels and patterns of spiritual practices and mindful awareness within convenience of teaching and learning students at a Midwest institution for higher learning. Literature observes an education focus on preparing children and youth for assimilation into a system of entrepreneurial profit and financialization and profit, at the expense of sacrificing personal identity and holistic wellness (Kumar \& Archarya, 2021; Widodo, 2019). Spirituality and mindfulness represent underappreciated aspects of teaching and learning that invite further teacher education research (Gillespie, 2021; Zimmerman, 2018). Therefore, it is critical to know what preservice teachers perceive spirituality and their understanding of mindfulness practice. This paper attempts to fill the literature gap by interpreting the attitudes towards spirituality and patterns of mindfulness practice within preservice teachers.

\section{LITERATURE REVIEW}

\section{Theoretical Framework}

The proposed framework, as well as the operational definitions that will be offered for spirituality and religion, are informed by the axiology of humanism in education. Humanist 
axiology is the branch of philosophy that examines what is intrinsically "good" or valued by a person (Pritchard et al., 2011). Examining the perceptions of preservice teachers by applying humanism in education engages varied student learning theories- the authors use Maslow and Mezirow as points of reference in understanding adult learning. Both theories offer a holistic viewpoint that explain the variety of needs humanity experiences to foster a deeper andragogical awareness for the teaching of preservice teachers.

Maslow's hierarchy of needs is "a theory of human motivation that relates these needs to general behaviour" (Wahba \& Bridwell, 1976, p. 213). Similar to other humanists, Maslow attempted to construct a psychological value system that would be derived from human nature, which included intrinsic values and the meta needs of self-transcendence (Koltko-Rivera, 2006).

Maslow's hierarchy of needs has influenced transformative learning theory, as seen in Mezirow's discussion (2012) of self-actualization stating that "hungry, homeless, desperate, threatened, sick, or frightened adults are less likely to be able to participate effectively in discourse to help us better understand the meaning of our own experiences" (Mezirow, p. 82). Further examination of transformative learning through the axiology of humanism invites educators to develop compassion, empathy, and awareness and to become further mindful of bias and worldview (Mezirow, 2000). By applying Maslow and Mezirow's humanistic lens to selfactualization invites spirituality and mindfulness as an important component for personal learning growth (Banez, 2016).

\section{Mindfulness and Spirituality}

Examining the perceptions of spirituality and mindfulness requires an understanding of the constructs. The researchers chose to operationalize spirituality based on Underwood's (2011) definition of spirituality, as the instrument used for the study pulls from Underwood's work in this study. Spirituality can be understood as facets of a human's life that include more than what we can see, touch, or hear (Underwood, 2011). Often, there are terminological challenges in defining spirituality, especially when understanding the nuances of spirituality amongst religion, morality, and values. Instead, we offer more of a secular understanding of the term, to be more encompassing of students enrolled in teacher education programs. Yet, the researchers highlight Palmer's (2003) definition as "the eternal human yearning to be connected with something larger than our own egos" for further context in education. (p. 377) This is important to note as spirituality has often been measured in terms of religiosity. Still, when analyzing in a secular setting, spirituality is often defined as a "search for the sacred" (Pargament, 1999, p. 12). This study also pays particular attention to the use of mindfulness as a form of contemplative practice to enhance a mindful disposition (e. $g$, trait mindfulness). Like spirituality, mindfulness has a wide array of definitions depending on the methodology studied (Chiesa et. al, 2011), but for this article, mindfulness will be defined as 'paying attention in a particular way, on purpose, in the present moment, and nonjudgmentally" (Kabat-Zinn, 1994, p. 4).

Theoretically, mindfulness is a practice rooted in spirituality (Trammel, 2017). However, the practice of mindfulness integrates varied elements that are foundational to many spiritual/religious practices. For example, curious awareness lends itself to high levels of trait mindfulness. In contrast, low trait mindfulness indicates that a person infrequently pays attention and awareness to the present moment and operates more on "auto-pilot" (Brown \& Ryan, 2003). Curating self-awareness is integral for mindfulness and is consistent in other spiritual/religious applications of breath, reverence, and solitude to create a deeper relationship to a higher power (Lutz, et al., 2015; Trammel, 2017). In sum, this may suggest that mindfulness 
is not ascribed to any religious tradition and can also be understood from a more secular point of view in the use of varied populations of practitioners (Siegel, 2007).

Although mindfulness and spirituality are two separate constructs, research has shown that the link between mindfulness and spirituality produces positive well-being results (Carmody et al., 2008; Shapiro et al., 1998; Wachholtz \& Pargament; 2005). Such processes of combining constructs offer possibilities for enhancing professional efficacy and achievement. A significant contributor to this spiritual growth and efficacy is work related to understanding the "inner self". Self-reflection and meditation have been shown to facilitate this attention to the self and contribute to greater awareness and a sense of purpose. Mindfulness and spirituality are means to achieve a contemplative path and are considered quite similar in practice. Jong (2013) researched the similarities in construct, suggesting that the similarity could mean that components of the two constructs are the overlapping qualities between mindfulness and spirituality. Jong also suggested the difference could mean that mindfulness facilitates a calm mind, while spirituality looks for the greater good. In the study of a more secular form of mindfulness, even MBSR has been shown to increase the perception of spirituality in daily life (Greeson et al., 2015). According to Greeson et al. (2015), mindfulness practices have similar outcomes and benefits to religious and spiritual practices, further overall well-being (Walsh \& Shapiro, 2006).

Acknowledgment of the contemplative and spiritual dimension in teaching and learning in the post-secondary context can contribute to knowing oneself more holistically. In this study, researchers explore preservice teachers' mindfulness and spiritual practices.

\section{Spirituality in Teacher Education}

There is little research available in the field of spirituality and teacher education preparation programs. More research is available when accounting for spirituality and post-secondary education, especially with the resurgence of religion and spirituality on college campuses within the past decade (Waggoner, 2016). Upon reviewing the literature on spirituality in education, research suggests students enrolled in the post-secondary school develop a more profound sense of self during their enrollment in higher education (Cady, 2007). Within student development of spirituality, certain characteristics of students enrolled in higher education have been studied. First, spirituality was consistently identified as central to greater awareness (Kessler, 2000; Miller, 2010). Other characteristics of spirituality in higher education are the connection to oneself, others, and their higher power- directly in reference to creating community (Chávez, 2001; Kessler, 2000; Lantieri, 2001; Miller, 2010; Oldnall, 1996; Palmer, 1998). Research also suggests when college students engage in deeper spiritual awareness, greater prosocial behavior also occurs (Raposa et al., 2016). In a longitudinal study conducted by the Higher Education Research Institute (2006) students reported using spirituality and religious activity to cope with their perceived stress. Those students who engaged in spirituality found more meaning in hardship on stress than those who did not engage in spiritual activity practices. To facilitate growth in spirituality, research has indicated that the greatest degree of growth has been measured through self-reflection, contemplation, or meditation.

\section{Mindfulness in Teacher Education}

Examples of holistic approaches to teacher education can be found in the cultivation of contemplative practices (Jennings \& DeMauro, 2017). Contemplative practices foster a deeper awareness of self, others, and spirit, which cultivates the awareness of humanity to a greater whole- like what Palmer (2003) discusses in his work on spirituality. Contemplative practices (meditation, mindfulness, and other practices that focus on increasing reflection and 
contemplation) allow for greater cognitive and emotional benefits, including decreased stress levels, increased self-worth, and promotion of resilience and well-being (Brown \& Ryan, 2003; Kabat-Zinn 1994). Within contemplative techniques, a variety of customs, habits, or rituals exist that act as a vehicle to spiritual insight (Bright \& Pokorny, 2013). Other benefits of the practice are increasing spiritual awareness by creating greater attention around our connectedness with ourselves and others, often facilitated by mindfulness and compassion (Bruce et al., 2018).

To understand mindfulness practices in the context of American education, a more westernized practice must be identified. In western culture, mindfulness and contemplative practices often remove the ethical and philosophical benefits of the practice. Often in the west, traditional eastern practices have been positioned through the lens of emotional or cognitive understanding, which tends to limit the resounding benefits of the practice. When foundational aspects of contemplation are removed, mindfulness may reinforce self-centered values where individuals privilege their personal identity over the care and compassion for others in their community (Davis \& BehmCross, 2020; Tan, 2020). In addition, mindfulness has been recognized as a spiritual act perro (Marlatt \& Kristeller, 2000). However, Kabat-Zinn (1994) and MBSR adapt mindfulness into a contemplative practice without adopting its spiritual origins. For this reason, we perceive spirituality as an integral component of contemplative practices that can continue to create pro-social behaviors for individual and community care.

Mindfulness and its foundations within Buddhist psychology have always included broader aspects of spirituality- inclusive of compassion and gratitude, as key components of mindfulness in Buddhist traditions are dedicated to alleviating inward and outward suffering (Germer \& Barnhofer, 2017). Offering compassion to oneself is an integral component of mindfulness and is a quality of contemplative practices as a whole and has been highly effective among college students (Smeets et al., 2014). Research has shown mindfulness and compassion, more specifically self-compassion has been helpful in healing perceived stress (Emery, 2020; Watson-Singleton et al., 2019). Interestingly, when the culture was accounted for in mindful compassion practices, more western cultures experienced challenges in offering selfcompassion. It was seen as considerably selfish to offer compassion to oneself first rather than compassion to others (Neff et al., 2008; Zhang et al., 2018) as traditional mindfulness practices offer awareness of suffering toward both oneself and others and do not exclude offering compassion to oneself.

In examining the literature on the use of mindfulness programs for preservice teachers, two mindfulness-based interventions are used frequently in education contexts: Mindfulness Based Stress Reduction (MBSR) developed by Kabat-Zinn (Frank et al., 2015; Sarah et al., 2016) and Cultivating Awareness and Resilience in Education (CARE) (Jennings \& DeMauro, 2017; Schussler et al., 2016). Research affiliated with these mindfulness interventions suggests that mindfulness offers the cultivation of a calm mind and body, despite external stressors. When looking at the impact of mindfulness on teachers, Perrone et al. (2006) found that teachers believed they were more effective when they thought there was spiritual connectedness or higher purpose with the work liperformed in the classroom. Participants who endorsed practicing some forms of meditation were also found to have a higher degree of reported spirituality than those who reported not practicing meditation (Perrone et al., 2006).

Upon reviewing the literature, there is a lack of applied research investigating the possibility of implementing or understanding spirituality and mindfulness in teacher education. Although there is available research within each independent variable, the combination or intersectionality of spirituality and mindfulness lacks in the field. Thus, we as researchers seek 
to examine the perception of mindfulness and spirituality amongst preservice teachers, to understand their beliefs and comprehension of the two variables. We hope this inquiry can help us better redesign teacher preparation courses to facilitate these discourses and understand preservice from a more holistic perspective to attend to their needs and reach their potentials.

\section{METHODS}

This paper conveys the results of a research study at a large public teacher education institution in the Midwest of the United States. It interpreted the spirituality practices and mindfulness awareness of a convenience sample of students. The findings are a component of a larger project that analyzed the effect of a classroom intervention on these practices and perceptions.

\section{Sample}

The sample consisted of enrollees in two undergraduate courses (a social studies methods course and a multicultural education course) during the spring 2021 semester and who consented to participate. There were 61 total enrollees in the two courses, of whom 53 completed the survey.

The survey respondents were predominantly white (46 or $86.8 \%$ ) females ( 48 or $90.6 \%$ ). The majority of the participants reported their academic class status as being seniors (35 or $66.0 \%)$, with eight (15.1\%) as juniors, nine (17.0\%) as sophomores, and one as a freshman. There were 48 students enrolled in the elementary education program and five enrolled in early childhood.

\section{Instrument}

The survey contained three sections, the first two of which drew from two separate measures. Spirituality practices were measured using items from the Daily Spiritual Experience Scale (Underwood, 2018) and mindfulness practices using the Mindful Attention Awareness Scale (Brown \& Ryan, 2003). The survey also sought information about student demographic information.

There were fifteen items drawn from the Daily Spiritual Experience Scale (DSES). Fourteen of the self-reported items were designed to assess the experiences of connection with spirituality in a respondent's daily life. The questions reflected wonder, gratitude, grace, a sense of connection with the spiritual. It also included measures of awareness of deep inner peace. Responses to the Likert-style items ranged from 1 (Almost Always) to 6 (Almost Never). (Underwood, 2018). An additional item asked about respondents' sense of closeness to God. It was scaled on a 5 - level basis.

The DSES scale was designed to capture the diverse experiences of spirituality, which may reflect both secular and religious undertones in multiple contexts. Upon review of the instrument, the scale has been used in numerous studies and is most often used to assess the health of religious/spiritual populations. However, this is now being extended to include other areas of interest (Underwood, 2011). In the construction of the DSES, Underwood noted the instrument's reliability across several studies with internal consistency (Underwood, 2002). In addition, evidence showed that daily spiritual experience is related to improved quality of life and positive mental health and social well-being (Underwood, 2011).

The other fifteen items were from the Mindful Attention Awareness Scale (MAAS). The MAAS, also known as the Day-to-Day Experiences Scale, consists of 15 items that focus on mindfulness traits. Trait mindfulness differs from state mindfulness in that the measurement questioned more mindfulness of disposition. Questions targeted a respondent's awareness of 
moment-to-moment presence.Responses to the Likert-style items ranged from 1 (Almost Always) to 6 (Almost Never).

In examining the validity of the MAAS scale, Brown and Ryan (2013) depicted good internal consistency and showed a positive correlation with the number of years of meditation practice. MAAS scores were also significantly higher among meditation practitioners than nonpractitioners (Brown \& Ryan, 2003). In examining the validity of MAAS, studies in varied contexts suggested the limitations of the instrument include the study of homogenous samples that have been used with the scale. More studies need to be done with a more diverse sample, for the validity of the instrument itself (Black et al., 2011).

Finally, the instrument contained a section that sought information concerning the respondents' identities and practices. Identity items were academic class, major, enrollment status, marital status, employment status, and residency status. Practice items consisted of religion, frequency of practice, and frequency of mindfulness practice.

\section{Analysis}

For this paper, we conducted descriptive and inferential statistical analysis to interpret selfreported spirituality and mindfulness levels and patterns of differences based on respondent traits.

Analysis of Spirituality Items. According to Underwood (2011), the DSES shows that more frequent daily spiritual experience is often represented by lower mean scores, which may allow for further individual item analysis. However, because of the exploratory nature of this research, we limit our findings to descriptive statistical analysis, recognizing that sample size may not be sufficient for varimax rotational analysis.

Concerning the analysis of MAAS items, Brown and Ryan (2003) constructed a 15-item questionnaire concerning trait mindfulness and examined the mean of the 15 items (collected in a Likert scale). When calculated, higher scores reflect higher levels of dispositional mindfulness (Brown \& Ryan, 2003). We performed descriptive analysis for each MAAS item and for the items mean. We also conducted a series of one-way ANOVAs to test for significant differences in mindfulness-based on respondent traits. However, we did not perform regression analysis due to a lack of a theoretical framework to guide the structure of potential independent variables.

\section{RESULTS}

This section describes the patterns of survey responses that relate to spirituality and mindfulness items. It contains two sections, one for each category. The spirituality section describes patterns associated with the 14 items containing the six-level Likert scale and then the remaining item concerning five levels. The mindfulness section provides the descriptive statistics for the items collectively, identifying those having the highest and lowest means. Inferential analysis describes any significant response differences based on respondent traits.

\section{Spirituality}

The means of responses to the 14 spirituality items based on the six-level scale ranged from 3.62 - or Somewhat Frequently - for Item 1 (I feel God's/Higher Power's Presence) to 5.41- or Very Frequently - for Item 11 (I feel thankful for my blessings). The items that yielded the lowest means concerned the respondents' sense of solicitation of, or desire for God's presence. The three items that yielded the highest means and five of the seven providing the highest means 
focused on self-security and relationship to the environment. Table 1 presents the items and the associated statistics.

Table 1. Descriptive Statistics associated with Spirituality Items $(n=53)$

\begin{tabular}{|c|c|c|c|c|c|}
\hline Item & Min. & Max. & $\begin{array}{l}\text { Mea } \\
\mathrm{n}\end{array}$ & SD & Skew \\
\hline 1. I feel God's/Higher Power's Presence & 1.00 & 6.00 & 3.62 & $\begin{array}{l}1.6 \\
7\end{array}$ & $(0.30)$ \\
\hline 2. I experience a connection to all living entities & 1.00 & 6.00 & 4.28 & $\begin{array}{l}1.2 \\
3\end{array}$ & $(0.44)$ \\
\hline 3. When connecting with God/Higher Power, I feel joy. & 1.00 & 6.00 & 4.13 & $\begin{array}{l}1.7 \\
3\end{array}$ & $(0.70)$ \\
\hline 4. Find Strength in Religion or Spirituality & 1.00 & 6.00 & 4.00 & $\begin{array}{l}1.7 \\
0\end{array}$ & $(0.51)$ \\
\hline 5. I Find Comfort in Religion or Spirituality & 1.00 & 6.00 & 4.23 & $\begin{array}{l}1.7 \\
4\end{array}$ & $(0.71)$ \\
\hline 6. Deep inner peace or harmony & 1.00 & 6.00 & 4.38 & $\begin{array}{l}1.2 \\
7\end{array}$ & $(0.64)$ \\
\hline 7. I ask for God's/Higher Power's help in daily activities & 1.00 & 6.00 & 3.72 & $\begin{array}{l}1.9 \\
2\end{array}$ & $(0.26)$ \\
\hline 8. I feel God's/Higher Power's love for me directly & 1.00 & 6.00 & 3.92 & $\begin{array}{l}1.8 \\
3\end{array}$ & $(0.40)$ \\
\hline 9. I feel God's/Higher Powers love through others & 1.00 & 6.00 & 4.17 & $\begin{array}{l}1.7 \\
1\end{array}$ & $(0.63)$ \\
\hline 10. I am spiritually touched by the beauty of creation & 1.00 & 6.00 & 4.66 & $\begin{array}{l}1.3 \\
9\end{array}$ & (0.99) \\
\hline 11. I feel thankful for my blessings & 1.00 & 6.00 & 5.42 & $\begin{array}{l}1.0 \\
6\end{array}$ & $(2.31)$ \\
\hline 12. I feel a selfless caring for others & 4.00 & 6.00 & 5.36 & $\begin{array}{l}0.7 \\
4\end{array}$ & $(0.69)$ \\
\hline $\begin{array}{l}\text { 13. I accept others, even when they do things that I think are } \\
\text { wrong. }\end{array}$ & 3.00 & 6.00 & 4.96 & $\begin{array}{l}0.8 \\
8\end{array}$ & $(0.28)$ \\
\hline 14. I desire to be closer to God or to be in union with him & 1.00 & 6.00 & 4.19 & $\begin{array}{l}1.7 \\
9\end{array}$ & $(0.65)$ \\
\hline
\end{tabular}

Those completing the survey also responded to a prompt that asked, "In general, how close do you feel to God?" The item provided five possible responses ranging from 1 (Not at all close) to 5 (Extremely close). The mean response of 2.92 indicated that respondents felt a sense of being somewhat close. Interestingly, twice (10:5), the number of respondents indicated being "Not at all close" compared to those responding being "Extremely close" to God.

\section{Mindfulness}

The means of responses to the 15 mindfulness items based on the six-level scale ranged from 2.96 - or Somewhat Infrequently - for Item 17 (I break or spill things because of carelessness, not paying attention, or thinking of something else.) to 4.36 - or Somewhat Frequently - for Item 28 (I find myself preoccupied with the future or the past.). Table 2 presents the items and the relevant information. 
The lowest means appear to be associated with items that involve matters of mindful automation. Respondents were not likely to be unfocused or engaged in subconscious habits. The higher means appear to be associated with items that concern distraction from the present. Respondents are preoccupied with their own thoughts and less focused on the world around them.

Table 2. Descriptive Statistics associated with Mindfulness Items $(n=53)$

\begin{tabular}{|c|c|c|c|c|c|}
\hline Item & Min. & Max. & $\begin{array}{l}\text { Mea } \\
\mathrm{n}\end{array}$ & SD & Skew \\
\hline $\begin{array}{l}\text { 16. I could be experiencing some emotion and not be aware of } \\
\text { it until later. }\end{array}$ & 2.00 & 6.00 & 4.19 & $\begin{array}{l}1.1 \\
3\end{array}$ & $(0.22)$ \\
\hline $\begin{array}{l}\text { 17. I break or spill things because of carelessness, not paying } \\
\text { attention, or thinking of something else. }\end{array}$ & 1.00 & 6.00 & 2.96 & $\begin{array}{l}1.3 \\
4\end{array}$ & 0.12 \\
\hline $\begin{array}{l}\text { 18. I find it difficult to stay focused on what's happening in the } \\
\text { present. }\end{array}$ & 1.00 & 6.00 & 4.02 & $\begin{array}{l}1.3 \\
8\end{array}$ & $(0.22)$ \\
\hline $\begin{array}{l}\text { 19. I tend to walk quickly to get where I'm going without paying } \\
\text { attention to what I experience along the way. }\end{array}$ & 1.00 & 6.00 & 4.11 & $\begin{array}{l}1.3 \\
5\end{array}$ & $(0.60)$ \\
\hline $\begin{array}{l}\text { 20. I tend to not notice feelings of physical tension or } \\
\text { discomfort until they really grab my attention. }\end{array}$ & 1.00 & 6.00 & 3.43 & $\begin{array}{l}1.4 \\
9\end{array}$ & $(0.14)$ \\
\hline $\begin{array}{l}\text { 21. I tend to forget a person's name. almost as soon as I've } \\
\text { been told it the first time. }\end{array}$ & 1.00 & 6.00 & 3.64 & $\begin{array}{l}1.3 \\
5\end{array}$ & $(0.24)$ \\
\hline $\begin{array}{l}\text { 22. It seems that I am "running on automatic" without much } \\
\text { awareness of what I'm doing. }\end{array}$ & 1.00 & 6.00 & 3.96 & $\begin{array}{l}1.2 \\
9\end{array}$ & $(0.61)$ \\
\hline 23. I rush through activities without being attentive to them. & 1.00 & 6.00 & 3.77 & $\begin{array}{l}1.3 \\
1\end{array}$ & $(0.06)$ \\
\hline $\begin{array}{l}\text { 24. I get so focused on the goal I want to achieve that I lose } \\
\text { touch with what I am doing. }\end{array}$ & 1.00 & 6.00 & 3.79 & $\begin{array}{l}1.1 \\
7\end{array}$ & $(0.71)$ \\
\hline $\begin{array}{l}\text { 25. I do jobs automatically, without being aware what I'm } \\
\text { doing. }\end{array}$ & 1.00 & 6.00 & 3.75 & $\begin{array}{l}1.3 \\
4\end{array}$ & $(0.37)$ \\
\hline $\begin{array}{l}\text { 26. I find myself listening to someone with one ear while doing } \\
\text { something else at the same time. }\end{array}$ & 1.00 & 6.00 & 4.02 & $\begin{array}{l}1.3 \\
8\end{array}$ & $(0.26)$ \\
\hline $\begin{array}{l}\text { 27. I drive to places on "autopilot" and then wonder why I went } \\
\text { there. }\end{array}$ & 1.00 & 6.00 & 3.30 & $\begin{array}{l}1.7 \\
8\end{array}$ & 0.22 \\
\hline 28. I find myself preoccupied with the future or the past. & 1.00 & 6.00 & 4.36 & $\begin{array}{l}1.1 \\
9\end{array}$ & $(0.74)$ \\
\hline 29. I find myself doing things without paying attention. & 1.00 & 6.00 & 3.72 & $\begin{array}{l}1.4 \\
1\end{array}$ & $(0.08)$ \\
\hline 30. I snack without being aware that I'm eating. & 1.00 & 6.00 & 3.02 & $\begin{array}{l}1.5 \\
0\end{array}$ & $(0.11)$ \\
\hline
\end{tabular}

Respondents appear to be preoccupied with their own internal musings; however, their spiritual focus relates to themselves and their material environment. Yet, they also tend not to feel close to the presence of God or another higher being, according to the DSES results. Interpretation of the MAAS scale reflects similar themes to the respondent's spirituality. Respondents appear distracted with simple day-to-day tasks, including eating and driving. The mindfulness of respondents, appears to have a direct relationship with the spirituality of respondents. 


\section{Inferential analysis}

We ran a series of one-factor analyses of variance (ANOVA) to interpret the presence of any significant differences in mindfulness between respondent traits. Significant differences were found based on an area of study. Early childhood majors $(\mu=4.92)$ expressed a significantly higher degree of mindfulness than elementary education majors $(\mu=3.61)$. There were not any other findings of significant difference in mindfulness-based on the measured traits or practices.

\section{DISCUSSION}

This study sought to interpret the attitudes towards spirituality and patterns of mindfulness practice within preservice teachers. It found that this sample of early childhood and elementary majors experienced a sense of spirituality rooted in self and the visible world and indicated respondents had a mindful sense that was disengaged from the external world.

Results of this study align with previous research that examined the constructs of spirituality and mindfulness, as the mindfulness of respondents appears to have a direct relationship with the spirituality of respondents (Greeson et al., 2015; Jong, 2013). Respondents overall did not feel close to a presence of God or another higher being and appeared less mindful of day to moment. As previous research has suggested (Greeson et al., 2015), a more mindful disposition is indicative of a higher awareness of the spiritual. Our data speak to this, as there confirmed a relationship between spirituality and mindfulness exists.

Our findings support research that indicates students in higher education are spiritual, yet the data indicates in a secular medium. The data depicts respondents appeared distracted with day-to-day happenings; however, their spiritual focus relates to themselves and their material environment. The findings reference a more westernized understanding of mindfulness and spirituality, and recent research has suggested that removing the more spiritual components of a contemplative practice could reinforce self-centered values where individuals privilege their personal identity and their day-to-day existence (Davis \& BehmCross, 2020; Tan, 2020) which was seen in participants' responses of their understanding and awareness of their own self. However, even with a more secular understanding of both mindfulness and spirituality applied, research suggests the endogenous relationship between the aforementioned constructs may facilitate greater transcendence and awareness of the self (Landau \& Jones, 2021).

Our findings also indicate a potential lack of understanding of what mindfulness means/is (Evans, 2019). This could also be due to the lack of understanding of the differences of mindfulness- especially within variations in state vs. trait mindfulness. The study focuses on the examination of trait mindfulness, or dispositional mindfulness, of preservice teachers. According to the results in the perception of mindfulness, many students reported their state of mindfulness as something that lacked continual receptive attention to what was/is taking place in the present, which may lead to a low indication of trait mindfulness (Brown \& Ryan, 2003). Encouraging preservice teachers to build their capacity for state mindfulness may create "mental space" to deeply experience spirituality and trait mindfulness, leading to a greater awareness of internal and external experiences (Labelle et al., 2015).

With a low to an average perception of trait mindfulness, preservice teachers should pursue further mindfulness training. Due to research supporting the direct relationship between the constructs of spirituality and mindfulness, mindfulness programs (inclusive of more secular programming) may be pursued. Important to note in this discussion is the variance in response amongst Early Childhood Education and Elementary Education programs. Future studies need 
to confirm these findings using samples that have a more balanced representation of educational programs. Regression analysis is not conducted for patterns of influence because no grounded theory is established to communicate these relationships. The authors recommend additional studies using larger samples to interpret patterns of causality.

\section{Limitations}

Results of this study drew from a convenience sample of teacher education students who completed an attitudinal survey. The employment of more diverse and robust populations using purposeful sampling processes could provide for more nuanced analyses. Although both mindfulness and spirituality have widely available research, mindfulness and spirituality are often conflated constructs that must be clearly defined when applied in combination. More research must be analyzed and added to the literature to clearly define the constructs of understanding and further awareness of the emerging themes within the study.

In addition to clarifying the constructs -depth, the sample of participants must be reconsidered to cast a wider net on who is included in the study. Due to the purposive sample used, the sample size of the groups is homogenous in population. As a result, it may be difficult to quantify a meaningful relationship within the variables. The sampling selection could be improved by obtaining a larger sample size, potentially by using preservice teachers outside of the classes selected for the study. The lack of diversity may fail to provide a clearer picture for a more generalizable population of preservice educators. Likewise, most data are self-reported by the selected sample. Self-reporting of inner states should be treated cautiously, as prior research reports that perception of inner states may appear disingenuous or lack awareness of self-knowledge (Nisbett \& Wilson, 1977). Future research may look at the possibilities of quantifiable measurements.

\section{CONCLUSION}

This study found that preservice teachers lacked a present moment awareness or state mindfulness which showed lower to average levels of perception in trait mindfulness. Respondents also reported being spiritually connected to the world but did not necessarily report a high perception of connectedness to a higher power. There appears to be a disconnect between internal and external self-awareness within preservice teachers. When looking at the intersectionality of the students' perceptions, we may differentiate what connection to meaning-making, awareness, and spirit look like to folks prior to entering the field- and it may be best suited to examine spirituality outside of religiosity. In Jon Kabat-Zinn's (1994) words, "perhaps 'spiritual' means simply experiencing wholeness and interconnectedness directly, a seeing that individuality and totality are interwoven, that nothing is separate or extraneous, and that everything is spiritual in the deepest sense, as long as we are there for it" (p. 182).

Continuing to cultivate the deeper meaning of teaching should happen prior to entering the classroom. Upon hire, the stressful environment of in-service teaching may diminish overall health and well-being (Farley \& Chamberlain, 2021; Newberry \& Allsop, 2017). Yet, due to the evidence presented in previous research, stating that both mindfulness and spirituality may alleviate burnout and increase efficacy- the need to include much more profound concepts of meaning-making may be beneficial in teacher preparation programs. Some teacher educators, such as Parker Palmer (2003), have suggested including the spirituality and deeper meaning of teaching in teacher preparation. Palmer wrote that spirituality is "the diverse ways we answer the heart's longing to be connected with the largeness of life-a longing that animates love and work, especially the work called teaching" (1998, p. 3). Such integration may facilitate other 
aspects of wellness, including but not limited to preparation in school life (Nieto, 2003), critical awareness of inequality (Marshall, 2009), and desire for inclusion (Edwards \& Perumal, 2017). Although the benefits are clear, perceptions and understanding of such constructs within teaching may not be. Thus, there is a greater need to put mindfulness-based practices into the curriculum to ascertain the meaning-making of pre-service teachers prior to entering the field.

\section{REFERENCES}

American Council on Education. (1937). The student personnel point of view. Author. American Council on Education. (1949). The student personnel point of view. Author.

Banez, A. M. (2016). A literature review of spirituality in the transformative learning process of students in higher education, with implications for online learning (Order No. 10118851). Available from ProQuest Central; ProQuest Dissertations \& Theses A\&I. (1795522774).

Black, D. S., Sussman, S., Johnson, C. A., \& Milam, J. (2011). Psychometric Assessment of the Mindful Attention Awareness Scale (MAAS) Among Chinese Adolescents. Assessment, 19(1), 42-52. https://doi.org/10.1177/1073191111415365

Bright, J., \& Pokorny, H. (2013). Contemplative practices in higher education: Breathing heart and mindfulness into the staff and student experience. HERDSA News, 35(1), 9-12. https://search.informit.org/doi/10.3316/informit.772823671454318

Brown, K. W., \& Ryan, R. M. (2003). The benefits of being present: Mindfulness and its role in psychological well-being. Journal of Personality and Social Psychology, 84(4), 822848. https://doi.org/10.1037/0022-3514.84.4.822

Bruce, M. A., Skrine Jeffers, K., King Robinson, J., \& Norris, K. C. (2018). Contemplative Practices: A Strategy to Improve Health and Reduce Disparities. International journal of environmental research and public health, 15(10), 2253. https://doi.org/10.3390/ijerph15102253

Cady, D. (2007). Spirituality and student development. In B. Speck, \& S. Hoppe (Eds.), Searching for spirituality in higher education, 97-109. Peter Lang.

Caldwell, Cam \& Hayes, Linda. (2016). Self-efficacy and self-awareness: moral insights to increased leader effectiveness. Journal of Management Development, 35, 1163-1173. https://doi.org/10.1108/JMD-01-2016-0011

Carmody, J., Reed, G., Kristeller, J., \& Merriam, P. (2008). Mindfulness, spirituality, and healthrelated symptoms. Journal of Psychosomatic Research, 64, 393-403.

Carlson, L.E. \& Brown, K.W. (2005) Validation of the Mindful Attention Awareness Scale in a Cancer Population. Journal of Psychosomatic Research, 58(1), 29-33. http://dx.doi.org/10.1016/j.jpsychores.2004.04.366

Chávez, A. F. (2001). Spirit and nature in everyday life: Reflections of a mestiza in higher education. New Directions for Students Services, 95, 69-79.

Chiesa, A., Calati, R., \& Serretti, A. (2011). Does mindfulness training improve cognitive abilities? A systematic review of neuropsychological findings. Clinical Psychology Review, 31(3), 449-464. https://doi.org/10.1016/j.cpr.2010.11.003

Darling-Hammond, L., \& Bransford, J. (Eds.). (2005). Preparing teachers for a changing world: What teachers should learn and be able to do. Jossey-Bass.

Davis, C., \& BehmCross, S. (2020) When Whiteness clouds Mindfulness: Using critical theories to examine mindfulness trainings for educators in urban schools, Equity \& Excellence in Education, 53(4), 583-597, https://doi.org/10.1080/10665684.2020.1791769 
Edwards, G., \& Perumal, J. (2017). Enacting Social Justice in Education Through Spiritual Leadership. Bulletin for Christian Scholarship, 82(3).

Evans, K. (2019). Preservice Teachers and Perceived Stress: A Comparative Study. [Dissertation]. Farley, A \& Chamberlain, L. (2021) The teachers are not alright: A call for research and policy on teacher stress and well-being, The New Educator, 17(3), 305-323, https://doi.org/10.1080/1547688X.2021.1939918

Gillespie, A. (2021). Spirituality in education. Professional accounts of the impact of spirituality on education. Emerald Publishing.

Greeson, J. M., Smoski, M. J., Suarez, E. C., Brantley, J. G., Ekblad, A. G., Lynch, T. R., \& Wolever, R. Q. (2015). Decreased Symptoms of Depression After Mindfulness-Based Stress Reduction: Potential Moderating Effects of Religiosity, Spirituality, Trait Mindfulness, Sex, and Age. The Journal of Alternative and Complementary Medicine, 21(3), 166-174. https://doi.org/10.1089/acm.2014.0285

Higher Education Research Institute. (2006). Spirituality in higher education: A national study of college students' search for meaning and purpose. Author. http://www.gseis.ucla.edu/heri/spirituality.html

Jennings, P. A., \& DeMauro, A. A. (2017). Individual-level interventions: Mindfulness-based approaches to reducing stress and improving performance among teachers. In T. M. McIntyre, S. E. Mclntyre, \& D. J. Francis (Eds.), Educator stress: An occupational health perspective (pp. 319-346). Springer International Publishing AG.

Jong, H. W. (2013). Mindfulness and spirituality as predictors of personal maturity beyond the influence of personality traits. Mental Health, Religion \& Culture, 16(1), 38-57. https://doi.org/10.1080/13674676.2011.644782

Kabat-Zinn, J. (1994). Wherever you go, there you are: Mindfulness meditation in everyday life. Hyperion.

Kessler, R. (2000). The soul of education: Helping students find connection, compassion and character at school. Association for Supervision and Curriculum Development.

Koltko-Rivera, M. E. (2006). Rediscovering the later version of Maslow's hierarchy of needs: Selftranscendence and opportunities for theory, research, and unification. Review of General Psychology, 10(4), 302-317. https://doi.org/10.1037/1089-2680.10.4.302

Kumar, A., \& Archarya, N. (2021). Critiquing critical instrumentalism in higher education. Lessons from teaching as meditative inquiry. Critical Education, 12(10), https://ices.library.ubc.ca/index.php/criticaled/article/view/186628

Labelle, L. E., Lawlor-Savage, L., Campbell, T. S., Faris, P., \& Carlson, L. E. (2015). Does self-report mindfulness mediate the effect of mindfulness-based stress reduction (MBSR) on spirituality and posttraumatic growth in cancer patients? Journal of Positive Psychology, 10(2), 153-166. https://doi.org/10.1080/17439760.2014.927902

Landau, S.D., \& Jones, F.W. (2021). Finding the Spiritual in the Secular: A Meta-analysis of Changes in Spirituality Following Secular Mindfulness-Based Programs. Mindfulness, 12, 1567-1581. https://doi.org/10.1007/s12671-021-01600-0

Lantieri, L. (2001). Schools with spirit: Nurturing the inner lives of children and teachers. Boston: Beacon Press

Lutz, A., Jha, A. P., Dunne, J. D., \& Saron, C. D. (2015). Investigating the phenomenological matrix of mindfulness-related practices from a neurocognitive perspective. American Psychologist, 70(7), 632-658. https://doi.org/10.1037/a0039585 
Marlatt, GA and Kristeller, JL. 2000. "Mindfulness and meditation". In Integrating spirituality into treatment, Edited by: Miller, W. 67-94. Washington: American Psychological Association.

Marshall, J.M. (2009). Describing the Elephant: Preservice Teachers Talk about Spiritual Reasons for Becoming a Teacher. Teacher Education Quarterly, 36, 25-44.

Mergler, A. G., \& Spooner-Lane, R. (2012). What Preservice Teachers need to know to be Effective at Values-based Education. Australian Journal of Teacher Education, 37(8), 6681. https://doi.org/10.14221/ajte.2012v37n8.5

Mezirow, J. (2000). Learning to think like an adult. In J. Mezirow \& Associates (Eds.), Learning as transformation: Critical perspectives on a theory in progress (pp. 3-33). San Francisco, CA: Jossey-Bass.

Mezirow, J. (2012). Learning to think like an adult: Core concepts of transformation theory. In The Handbook of Transformative Learning: Theory, Research, and Practice. Wiley.

Miller, J. (2010). Whole child education. University of Toronto Press.

Newberry, M., \& Allsop, Y. (2017). Teacher attrition in the USA: The relational elements in a Utah case study. Teachers and Teaching, 23, 863-880. https://doi.org/10.1080/13540602.2017.1358705

Nieto, S. (2003). What keeps teachers going? Teachers College Press.

Nisbett, R. E., \& Wilson, T. D. (1977). The halo effect: Evidence for unconscious alteration of judgments. Journal of Personality and Social Psychology, 35(4), 250-256.

Noddings, N. (2010). Moral Education in an Age of Globalization, Educational philosophy and theory, 42(4), 390-396, https://doi.org/10.1111/j.1469-5812.2008.00487.x

Oldnall, A. (1996). A critical analysis of nursing: Meeting the spiritual needs of patients. Journal of Advanced Nursing, 23, 138-144.

Palmer, P. J. (1998). The courage to teach: Exploring the inner landscape of a teacher's life. Jossey-Bass Publishers.

Palmer, P. J. (2003). Teaching with Heart and Soul. Journal of Teacher Education, 54(5), 376-385. https://doi.org/10.1177/0022487103257359

Pargament, K. I. (1999). The psychology of religion and spirituality? Yes and no. The International Journal for the Psychology of Religion, 9, 3-16.

Perrone, K.M., Webb, L.K., Wright, S.L., Jackson, Z.V., \& Ksiazak, T.M. (2006). The relationship of spirituality to work and family roles and life satisfaction. Journal of Mental Health Counseling, 28(3), 253-268. https://doi.org/10.17744/mehc.28.3.81a1dlhwelblce0v

Pritchard, A., Morgan, N., \& Ateljevic, I. (2011). Hopeful tourism: A New Transformative Perspective. Annals of Tourism Research, 38(3), 941963. https://doi.org/10.1016/j.annals.2011.01.004

Raposa, E. B., Laws, H. B., \& Ansell, E. B. (2016). Prosocial Behavior Mitigates the Negative Effects of Stress in Everyday Life. Clinical psychological science: a journal of the Association for Psychological Science, 4(4), 691-698. https://doi.org/10.1177/2167702615611073

Shapiro, SL, Schwartz, GE and Bonner, G. 1998. Effects of mindfulness-based stress reduction on medical and premedical students. Journal of Behavioral Medicine, 21, 581-599.

Siegel D. J. (2007). Mindfulness training and neural integration: differentiation of distinct streams of awareness and the cultivation of well-being. Social cognitive and affective neuroscience, 2(4), 259-263. https://doi.org/10.1093/scan/nsm034

Smeets, E., Neff, K., Alberts, H., \& Peters, M. (2014). Meeting suffering with kindness: Effects of a brief self-compassion intervention for female college students. Journal of Clinical Psychology, 70(9), 794-807. https://doi.org/10.1002/jclp.22076 
Tan, H., Rumbold, B., Gardner, F., Glenister, D., Forrest, A., Bowen, L. (2020). How is spiritual care/pastoral care understood and provided in general hospitals in Victoria, Australia? Staff perspectives. Journal for the Study of Spirituality, 10(2), 114-126. https://doi.org/10.1080/08854726.2020.1793095

Trammel, R. C. (2017). Tracing the roots of mindfulness: Transcendence in Buddhism and Christianity. Journal of Religion \& Spirituality in Social Work: Social Thought, 36(3), 367383. https://doi.org/10.1080/15426432.2017.1295822

Underwood, L. G. (2011). The Daily Spiritual Experience Scale: Overview and Results. Religions, 2(1), 29-50. http://dx.doi.org/10.3390/rel2010029

Wachholtz, A. B. and Pargament, K. I. 2005. Is spirituality a critical ingredient of meditation? Comparing the effects of spiritual meditation, secular meditation, and relaxation on spiritual, psychological, cardiac, and pain outcomes. Journal of Behavioral Medicine, 28: 369-384.

Waggoner, M. (2016) Spirituality and Contemporary Higher Education, Journal of College and Character, 17:3, 147-156, https://doi.org/10.1080/2194587X.2016.1195752

Wahba, M. A., \& Bridwell, L. G. (1976). Maslow reconsidered: A review of research on the need hierarchy theory. Organizational Behavior and Human Performance, 15, 212-240.

Walsh, R., \& Shapiro, S. L. (2006). The meeting of meditative disciplines and western psychology: A mutually enriching dialogue. American Psychologist, 61(3), 227-239. https://doi.org/10.1037/0003-066x.61.3.227

Widodo, H. (2019). The role of school culture in holistic education development in Muhammadiyah Elementary School Sleman Yogyakarta. Dinamika IImu, 19(2), 265-285. https://doi.org/10.21093/di.v19i2.1742

Zeichner, K. (2016). The changing role of universities in US teacher education. In B. Moon (Ed.), Do universities have a role in the education and training of teachers? An international analysis of policy and practice, (pp. 107-126). Cambridge: Cambridge University Press.

Zhang, K., \& Wu, D. I. (2016). Towards a holistic teacher education: Spirituality and special education teacher training. In de Souza, M., Bone, J., \& Watson, J. (Eds.), Spirituality across Disciplines: Research and Practice (pp,135-147). Springer.

Zimmerman, A. (2018). Considering the prospect of cultivating mindfulness in teacher education. Issues in Teacher Education, 27(1), 57-72. https://www.itejournal.org/issues/spring-2018/08zimmerman.pdf 